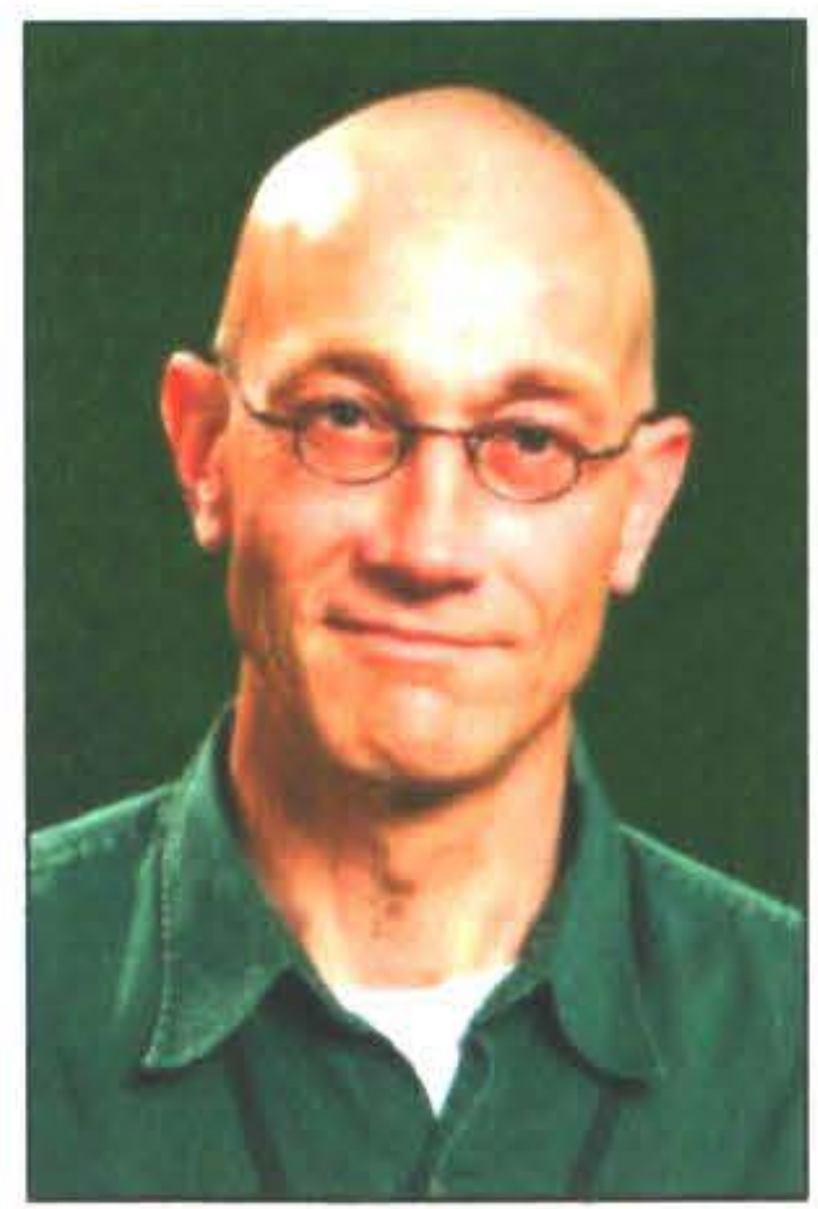

\title{
PRELIMINARY LEADING \\ INDICATORS OF EMPLOYMENT \\ IN NEW ZEALAND: \\ RECENT RESULTS
}

\author{
Dirk van Seventer
}

Department of Labour

The Department of Labour is currently testing a number of Leading Indicator of Employment (LIoE) series. These indicators are aggregations of different series into a single composite index. The LIoE series are designed to give advance warning of turning points in employment. The series have been shown to lead cyclical employment consistently over a long period. Results for recent periods are discussed in more detail as they show deviations from the close historic relationship. This may indicate fundamental shifts in the New Zealand labour market.

\section{Introduction}

The Department of Labour (DoL) is currently testing a number of Leading Indicator of Employment (LIoE) series. These indicators are aggregations of a number (five or six) of different series into a single overall composite index. The series have historically shown to lead cyclical employment. The LIoE series are designed to give advance warning of turning points in employment, which is defined as the number of people in paid work of one hour or more per week as per the Household Labour Force Survey (HLFS).

Monitoring and developing an outlook of employment in New Zealand is seen as an important tool for DoL as part of its labour market monitoring functions. It was suggested that DoL develop, establish and maintain a Leading Indicator of Employment for New Zealand as it could enhance DoL's capability to monitor labour market development and develop employment outlooks.

A Treasury working paper (Claus \& Claus, 2002) describes the construction of a leading indicator model of New Zealand employment, but this has not been maintained. The Australian Department of Education Employment and Workplace Relations (DEEWR) maintains a Leading Indicator of Employment that was developed to give advance warning of turning points in cyclical employment.

The DoL has a statutory obligation to review the minimum wage in New Zealand. A Leading Indicator of Employment was seen as potentially making an important contribution to the consideration of room for minimum wage increases.

The average lead time of the Indicator (i.e., the time between a peak or trough in the Indicators and the corresponding peak or trough in employment) is supposed to be around two to three quarters. A 'turning point' in the LIoE (or employment) series is confirmed when there are two consecutive quarterly movements in the same direction after a local peak or trough.

\section{Method and Series Included}

As our main model we adopt the concordance approach developed by Claus (2006) to compile a composite index. The weights of the relevant components are based on the number of quarters that the component series and the employment series move in the same direction. The components were selected by Claus (2006) after a process based on regression analysis and theory. We summarise and provide comments below.

Job Vacancy Ads can be an important leading indicator of employment as employers make their hiring intention clear. Early draft versions of the DoL Leading Indicator of Employment therefore included a Job Ads series previously maintained by ANZ. When the series was terminated by ANZ, it was dropped as a component of the DoL LIoE. Moreover, as the ANZ Job Ads series started in 1990, dropping this series also allowed the other series (discussed below), to go back further to 1986 and thereby picking up an earlier employment cycle. This eventually became the "Standard LIoE" presented below. Recently, the DoL has taken over the ANZ Job Ads Series (see Silverstone \& Wall, 2008) and it has now been reintroduced into an "Expanded LIoE". The Australian Department of Education Employment and Workplace Relations (DEEWR) has used the Australian ANZ Job Ads series as one of the components of their monthly Leading Indicator of Employment. Although it is noted by DEEWR that the importance of job ads has declined over time, their Leading Indicator of Employment method still incorporates the ANZ Job Ads series with a weight of $44 \%$. 
The QSBO Labour as the main Limiting Factor may indicate future hiring activities, while the tax receipts published by the New Zealand Treasury can be regarded as an indicator of economic activity. Share price indices can be seen as an indicator of financial wealth and associated demand pressures and performance of the economy. Immigration is another potentially important indicator of domestic activity in New Zealand and hence employment. Immigration in New Zealand tends to be procyclical. During the mid-1990s and early 2000s, for example, an increase in permanent long-term migration has been associated with demand pressures, residential construction upswing and an increase in employment.

Variables indicating weather conditions may also lead changes in domestic activity with adverse weather conditions putting downward pressure on agricultural and other output (such as electricity generation) and associated employment. The Southern Oscillation Index (SOI) is based on the difference in air pressure between Darwin in Australia and Tahiti in French Polynesia and persistent positive values are associated with La Niña conditions, which have a weak impact on climate in New Zealand with more rain in the northeast of the North Island caused by more north-easterly winds. El Niño conditions are often indicated by a period of negative SOI values, which are usually accompanied by more westerly winds that can lead to more rain in the west and drought in the east. A lower index is expected to have a negative influence on employment because $\mathrm{El}$ Niño conditions can have a strong negative impact on agricultural output and employment.

However, the relationship between weather patterns and economic activity is not clear cut. More recently, positive SOI levels and associated La Niña conditions have been related to abnormal dry conditions, in particular in the Waikato dairy farming area, with downward pressures on economic activity in agriculture, as explored in the next table.

Table 1: Southern Oscillation Index (quarterly change) and Agriculture GDP (quarterly percentage change)

\begin{tabular}{|r|rrl|} 
& \multicolumn{1}{c}{$\begin{array}{c}\text { Agr GDP } \\
\text { Q \% Ch }\end{array}$} & \multicolumn{1}{c|}{ SOI } & Q Ch \\
& \multicolumn{1}{c}{ Q Comment } \\
\hline Jun-06 & $-3.6 \%$ & 0.0 & \\
\hline Sep-06 & $-0.37 \%$ & -9.97 & El Nino \\
Dec-06 & $0.74 \%$ & -6.57 & El Nino \\
Mar-07 & $-2.26 \%$ & -3.80 & El Nino \\
\hline Jun-07 & $-0.25 \%$ & -0.23 & El Nino \\
Sep-07 & $-0.75 \%$ & -0.03 & El Nino \\
Dec-07 & $3.1 \%$ & 9.9 & La Nina \\
\hline Mar-08 & $-5.4 \%$ & 15.9 & La Nina \\
\hline Jun-08 & $-0.6 \%$ & 1.7 & La Nina \\
\hline Sep-08 & & 12.2 & La Nina \\
\hline Dec-08 & & & \\
\hline
\end{tabular}

Source: SNZ National Accounts, Australian Bureau of Meteorology

\section{Results}

As mentioned above, two LIoE series are explored, one with and one without a Job Ads series that is currently maintained at DoL. As discussed by Claus (2006), the Standard LIoE has performed well historically, giving advanced warnings for a number of employment cycles in the late 1980s and during the 1990s. The Expanded version has performed equally well historically. Below we focus on more recent results.

\section{a) Standard LIoE: excluding the Job Ad Series}

The Leading Indicator of Employment excluding the Job Ad Series declined for the fourth consecutive time in the September 2008 quarter after rising for four consecutive quarters prior to this turnaround. A decline in this Leading Indicator of Employment was already confirmed as a downward turning point in the last quarter of 2007. However, it has not yet showed up as a fall in employment in the HLFS, which rebounded in the second quarter of 2008 from a decline in the previous quarter, and maintained a slight upward trend in the third quarter. Based on the composition of the ingredient components, the latest results of the Leading Indicator of Employment suggest increasingly downward risks to employment growth during the remained of 2008 and early 2009.

\section{b) Expanded LIoE: Including the Job Ad Series}

Recently, the Job Ad Series was reintroduced in the LIoE after the series was discontinued by ANZ and taken over by DoL for internal labour market monitoring purposes. This series is, however, only available over a shorter period. The LIoE version that includes the Job Ad Series also confirmed a downturn in the December 2007 quarter as it followed a downturn in the previous quarter (September 2007). In the current quarter a further downturn is reported which reinforces the strong negative outlook for employment over the next three quarters.

\section{c) Recent results for components of the Leading Indicator of Employment}

As expected, most of the components of the Leading Indicator of Employment Series paint a negative picture for employment in the near term. The Job Ad Series shows a further decline compared to the previous quarter. The QSBO indicator of labour as the main limiting factor has declined further compared to the previous quarter and at a faster rate. The change in company tax receipts (seasonally adjusted) made a further negative contribution to the leading indicator (after seasonally adjustment). Permanent and Long Term arrivals declined after an increase in the previous quarter (after seasonally adjustment). The decline to a low, albeit still positive, level by the Southern Oscillation Index in the previous quarter only lasted for a single quarter and turned significantly positive again this quarter, suggesting weak weather pattern impacts. The stock market index continues to make a negative contribution. 
Figure 1: Employment and Leading Indicator of Employment (standard, i.e., excluding the Job Ad Series)

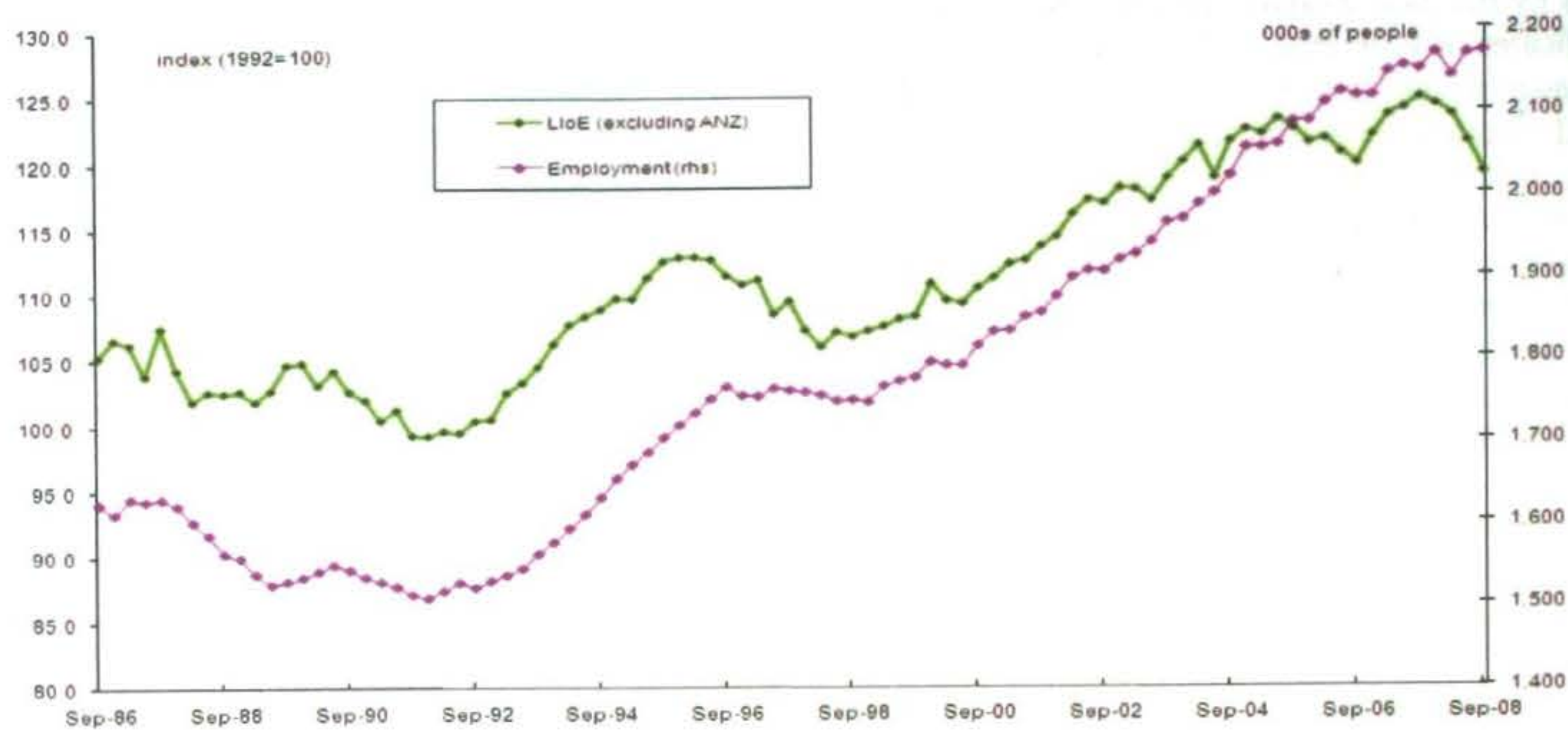

Source: DoL, Statistics New Zealand

Figure 2: Employment and Leading Indicator of Employment (including the Job Ad Series)

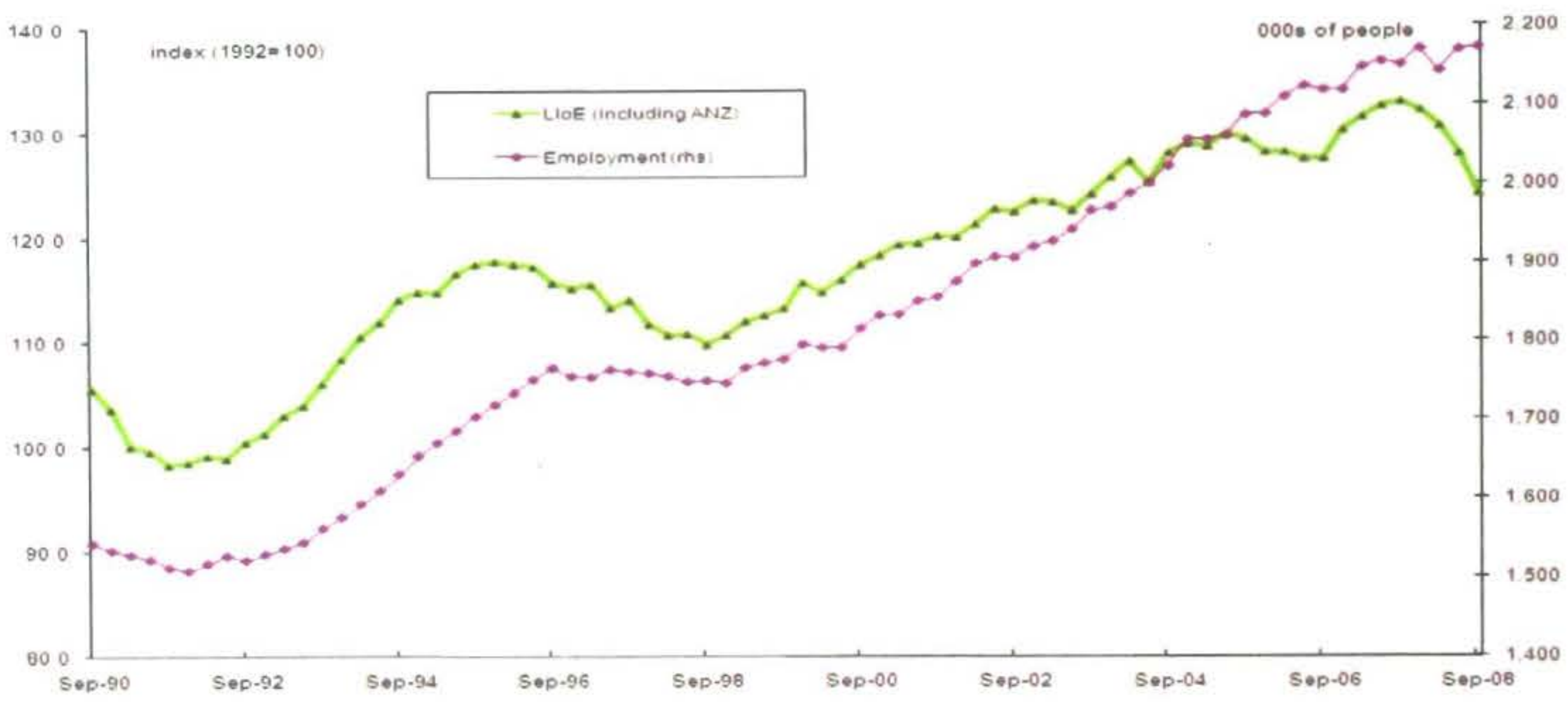

Source: DoL, Statistics New Zealand

Table 2: Leading Indicator Components (seasonally adjusted where necessary)

\begin{tabular}{|c|c|c|c|c|}
\hline Component & $\begin{array}{l}\text { Quarterly change } \\
\text { Jun } 2008 \text { Quarter }\end{array}$ & $\begin{array}{l}\text { Quarterly change } \\
\text { Mar } 2008 \text { Quarter }\end{array}$ & $\begin{array}{c}\text { Weight } \\
\text { in Index } \\
\text { latest quarter incl Job } \\
\text { Vac Ads }\end{array}$ & $\begin{array}{c}\text { Weight } \\
\text { in Index } \\
\text { latest quarter excl Job } \\
\text { Vac Ads }\end{array}$ \\
\hline 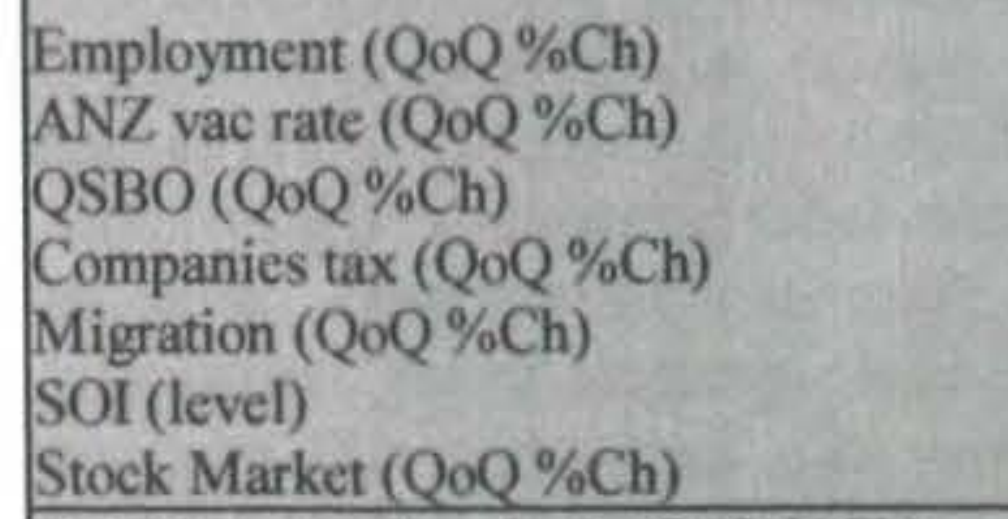 & $\begin{array}{c}0.1 \% \\
-15.6 \% \\
-33.4 \% \\
-4.1 \% \\
-0.8 \% \\
12.2 \\
-6.6 \% \\
\end{array}$ & $\begin{array}{c}1.3 \% \\
-7.5 \% \\
-8.9 \% \\
-19.1 \% \\
6.3 \% \\
1.7 \\
-4.7 \% \\
\end{array}$ & $\begin{array}{l}18.2 \% \\
18.6 \% \\
15.4 \% \\
19.8 \% \\
13.0 \% \\
15.0 \% \\
\end{array}$ & $\begin{array}{l}22.3 \% \\
19.3 \% \\
22.7 \% \\
17.0 \% \\
18.6 \% \\
\end{array}$ \\
\hline $\begin{array}{l}\text { LIoE (standard excl ads, QoQ \% Ch) } \\
\text { LioE (expanded, incl adds, Q0Q \% Ch) }\end{array}$ & $\begin{array}{l}-1.9 \% \\
-2.9 \%\end{array}$ & $\begin{array}{l}-1.7 \% \\
-2.9 \%\end{array}$ & & \\
\hline
\end{tabular}

Note: It is the levels of the components, and not the percentage changes, that collectively influence the monthly movements in the Leading Indicator. SOI is shown in level changes. 
a) QSBO Limiting Factor: labour (seas adj)

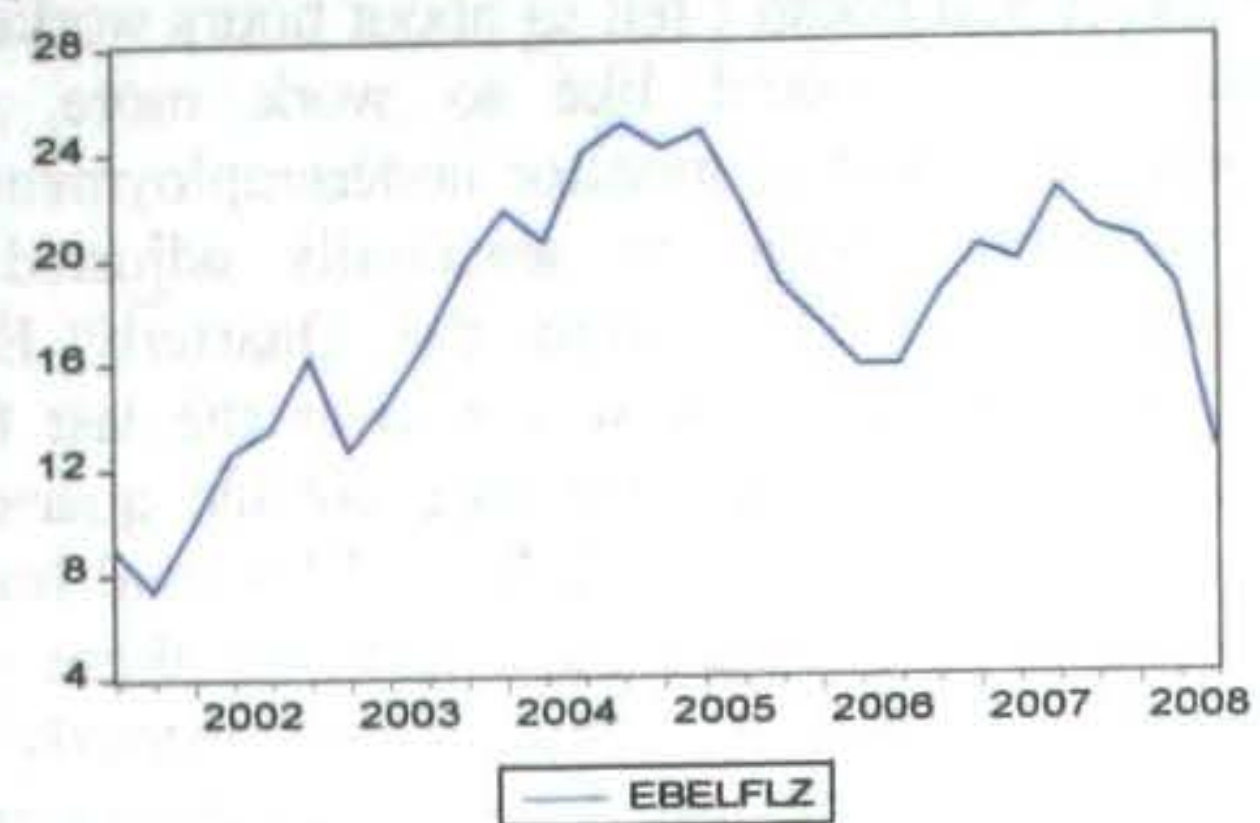

c) Quarterly PLT Arrivals (seas adj)

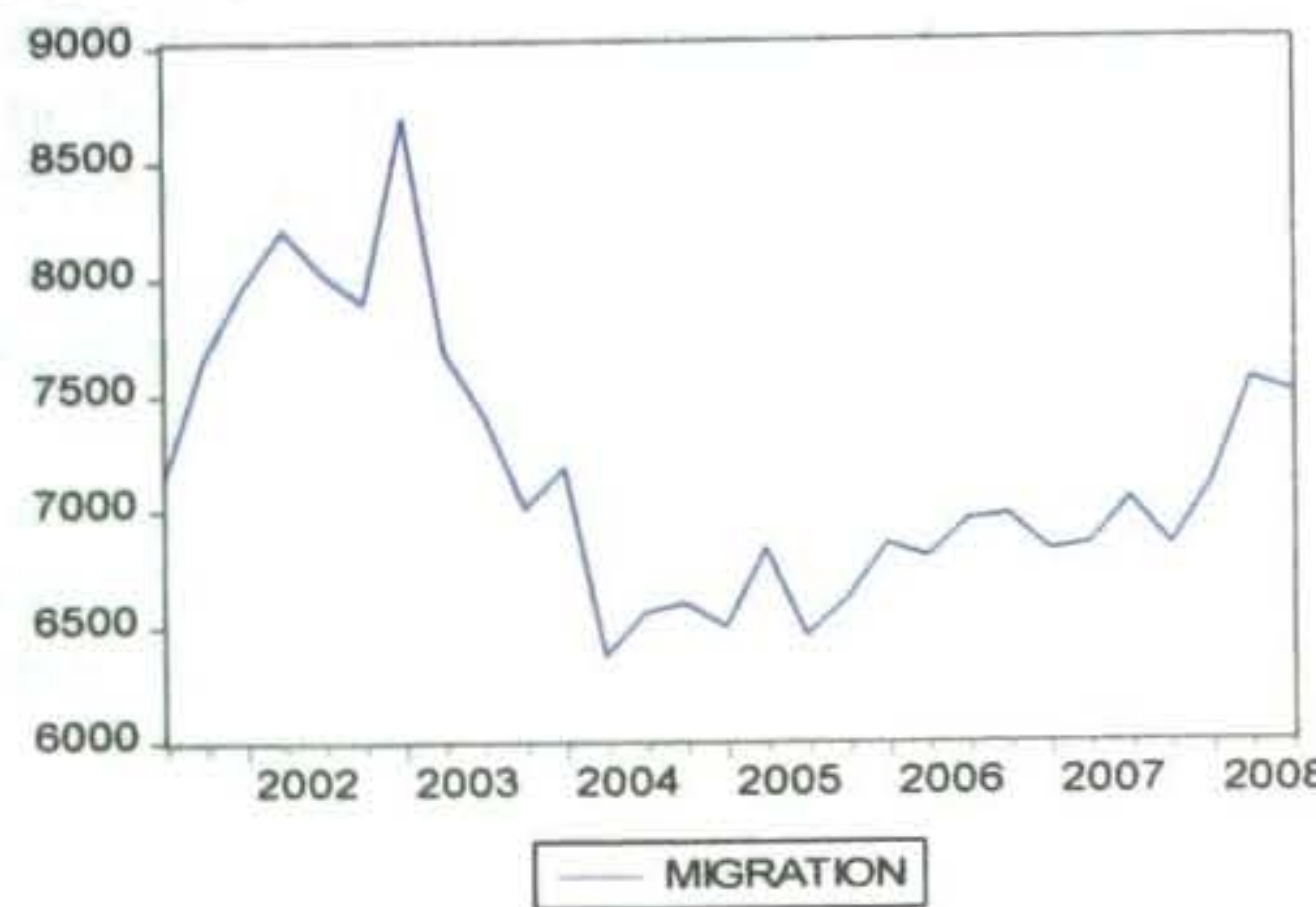

e) Stock Market (share price index)

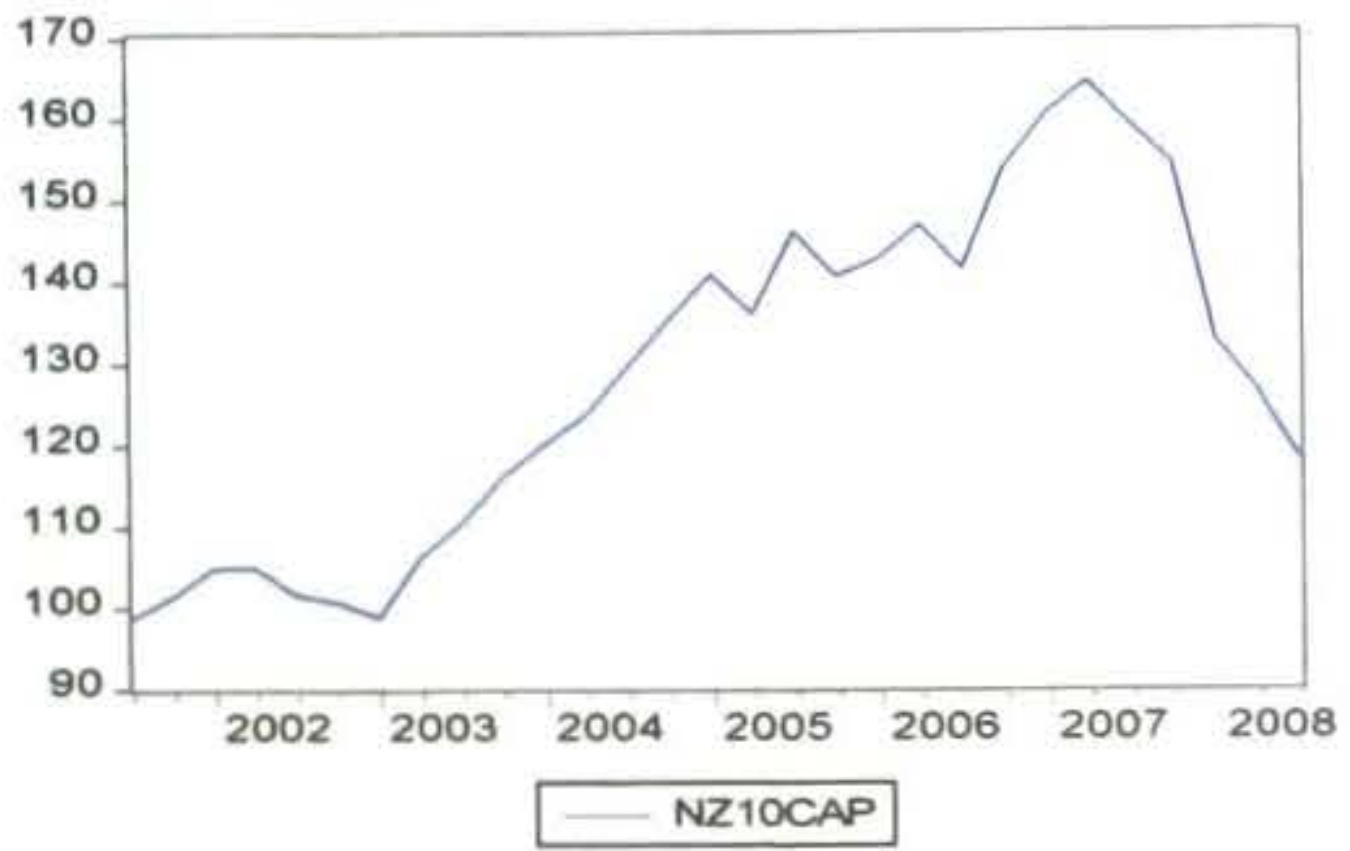

\section{Recent Performance}

While in the more distant past both Leading Indicators of Employment have functioned well in terms of leading turning points in the employment cycles, a cursory glance at the change in levels suggests that over the whole period, employment has risen faster than the LIoE than employment. Significant falls in the LIoE series can be associated with smaller declines in employment or slowdown in the growth of it. Consequently, one could argue that any turning point in the LIoE may not necessarily result in a turning point in employment. The signalling of turning points just considers the direction of change (increases and declines) of the index compared to the direction of change in employment. This is independent of the size of the changes.

Nevertheless, the more recent performance has been less convincing. To examine this more closely we show the last 8 years of the "Standard LIoE" (i.e., excluding the Job Ads series) and employment in Figure 4. b) Corp Tax (gr receipts - refunds, seas adj)

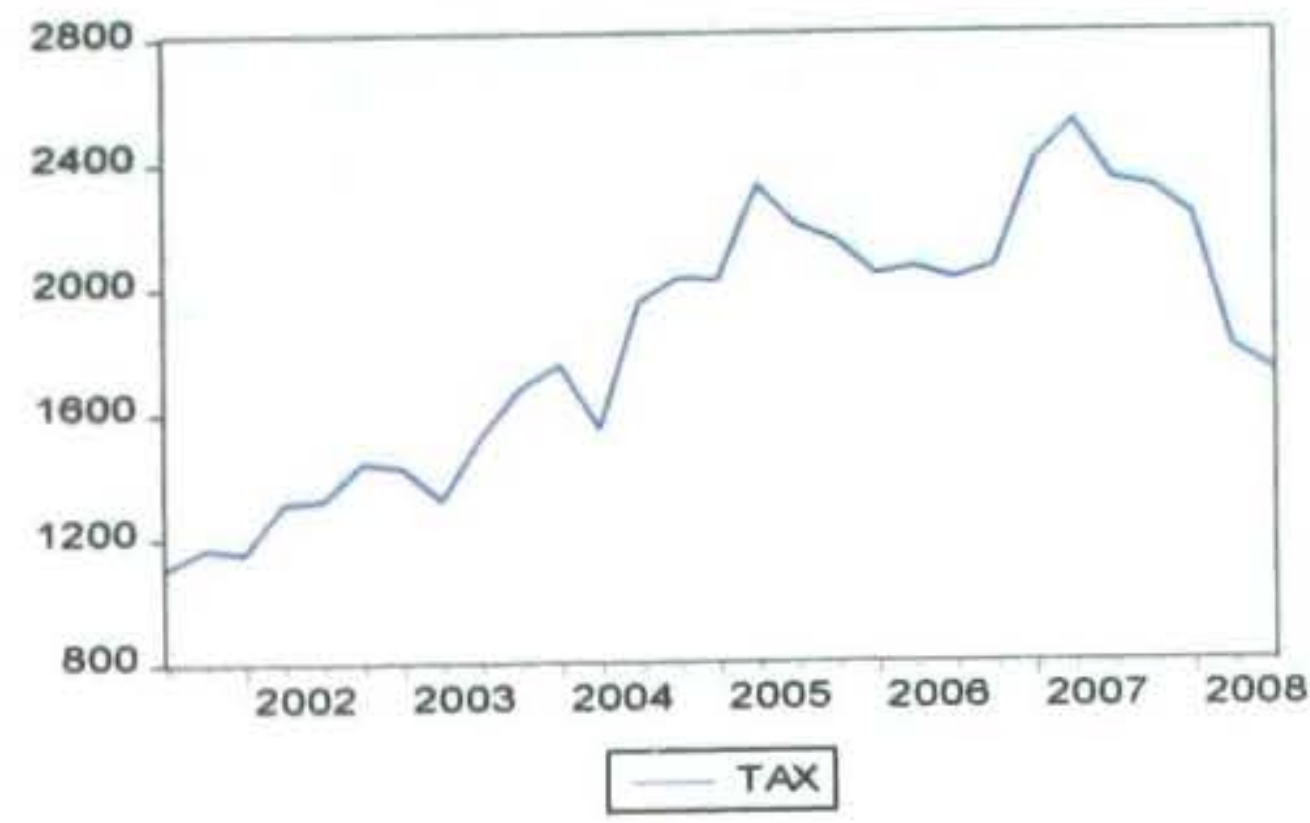

d) Southern Oscillation Index

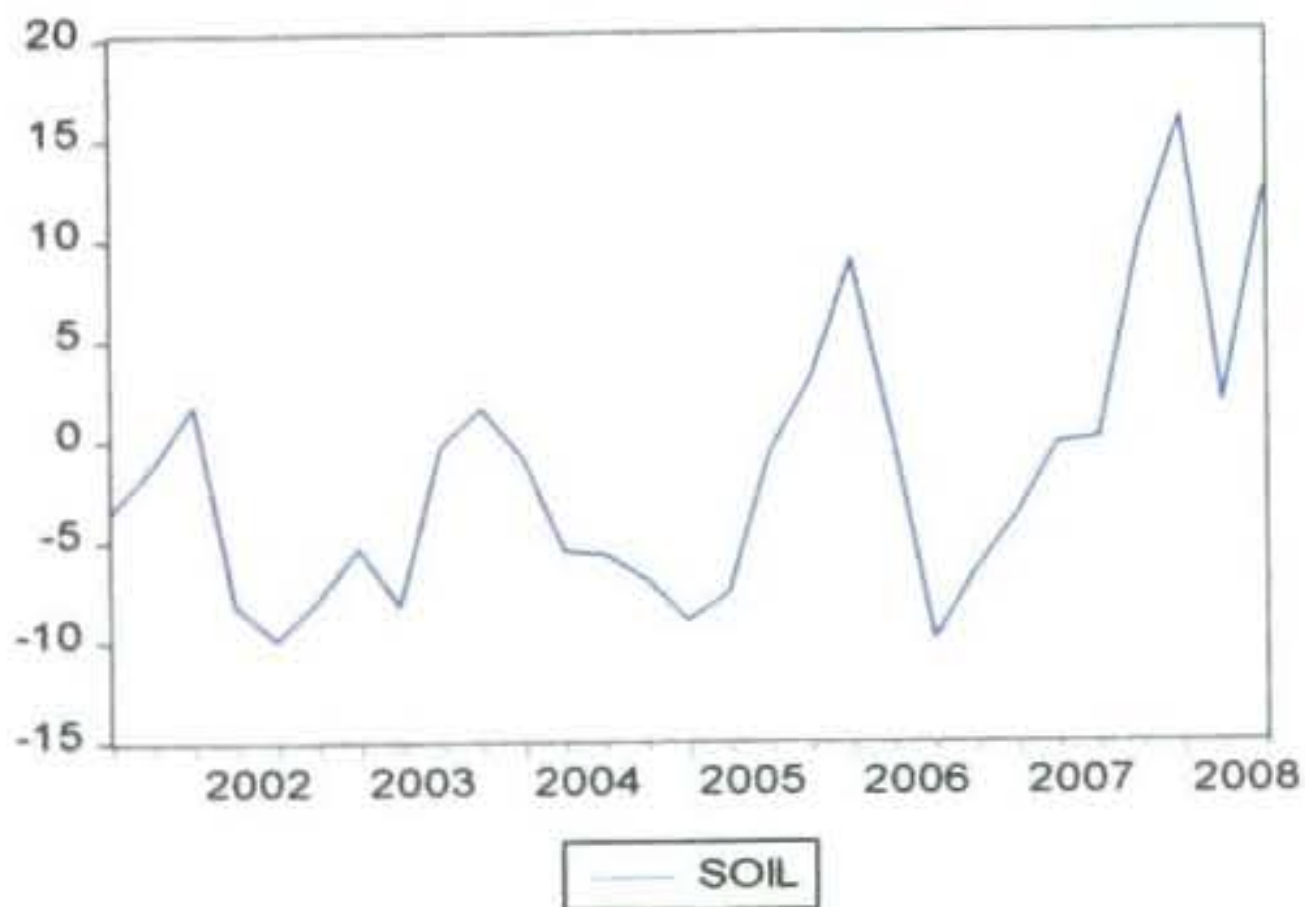

f) Job Ad Series (seas adj)

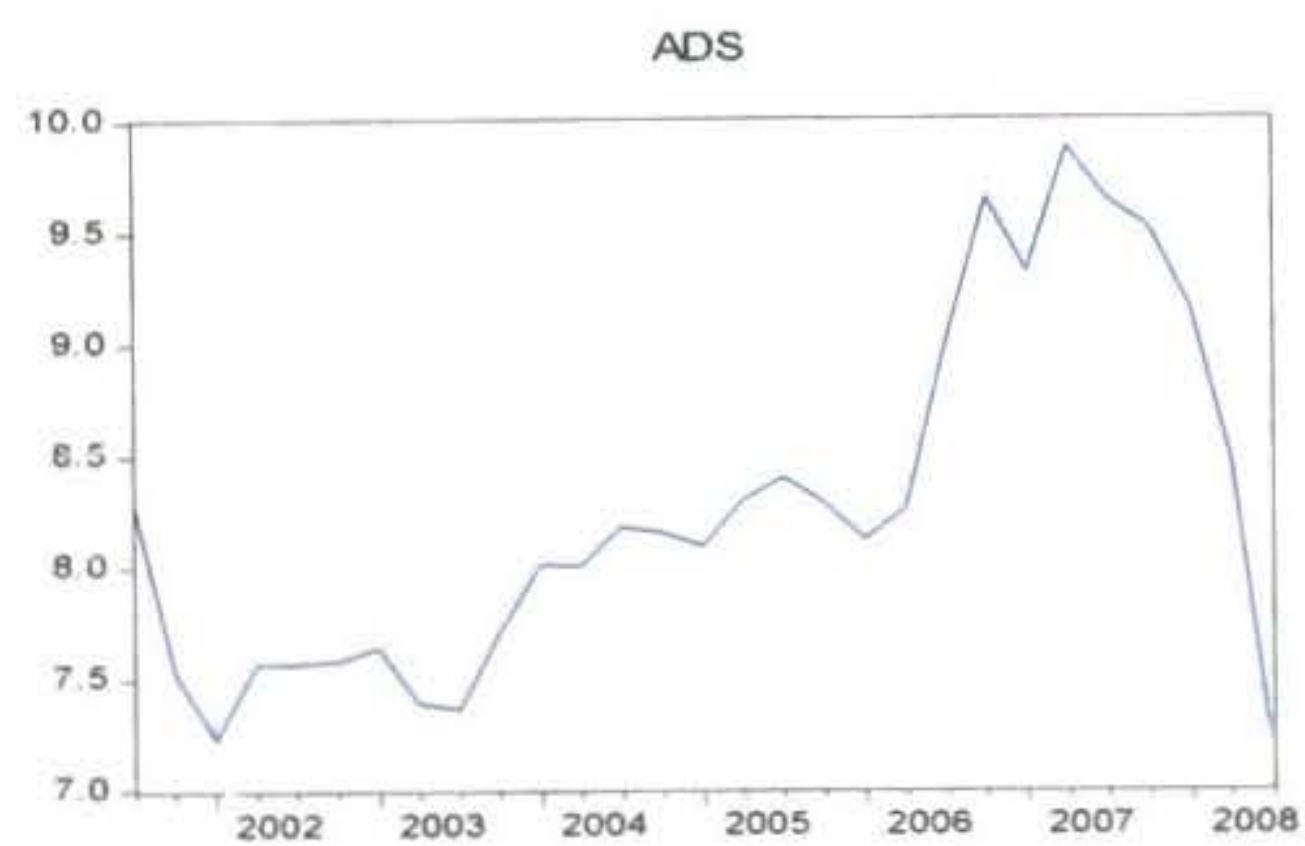

Over the last 8 years the employment cycle has been pointing upwards and has not confirmed a single downturn, i.e., there has been not a single occasion in which quarterly percentage change in employment has been negative more than once in a row. The LIoE, however, went into a short downturn of 2 quarters, from December 2002 to June 2003, which would have suggested a downturn in employment from June 2003 onwards for two quarters. Instead, quarterly employment growth was positive. This is a rather short period of incorrect warning of employment downturn compared to the downturn in the LIoE that started in June 2005 and lasted 5 quarters. Again, employment continued robust growth during this period except for the mild contraction at the end which lasted only a single quarter and therefore does not constitute a turning point.

The most recent downturn in the LIoE was recorded from September 2007 onwards, is still in progress and has now lasted 4 quarters. Employment declined during the first quarter of 2008 but this was reversed in the second quarter followed by a further small increase in the $3^{\text {rd }}$ 
quarter of 2008. Although not shown here, a similar pattern emerges if we include the Job Ads series into the mix.

The jury is still out on what direction employment will take in the December 2008 quarter, but even if it does turn negative, a downturn can only be confirmed with a further quarter on quarter proportional decline in the first quarter of 2009. The LIoE would then have advanced a confirmed downturn in employment by 5 quarters, which is longer than is suggested by the literature.

Still, a downturn in the LIoE is not out of the ball park compared to recent market opinion. Indeed, 4 of the 6 series used in the DoL LIoE series have declined over the last 5 quarters, including the QSBO labour as a limiting factor index, company tax receipts, the share price index and the job ad series. In addition, based on quarterly percentage change, GDP growth (seasonally adjusted) has been negative during the first two quarters of 2008 .

The question then is why employment has continued to increase while economic indicators are heading the other way. The usual explanation that is offered centres around the labour hoarding argument, with firms' desire to hang onto workers in case the economic downturn is short lived and labour will be hard to come by, as has been the case in the last 8 years or so. The other argument that is offered is that part-time work has increased recently. Thus, while the employment indicator series is the official measure of employment, it does include part-time workers and doesn't tell us about hours worked and parttimers who would like to work more, a measure sometimes used to monitor underemployment. Quarterly percentage change of seasonally adjusted full time equivalents (FTEs) from the Quarterly Employment Survey (QES) has, however, over the last 8 years not been negative except for two isolated quarters. Similar observations can be made for HLFS total hours worked and QES total hours paid, none of these series have reported more than a few isolated quarterly percentage declines over the last 8 years. No downturns in these series have been confirmed apart from HLFS hours worked during a 2 quarter period of September 2002 to March 2003, which seems to preclude the short 2 quarter downturn in the LIoE that started in December 2002.

However, part-time employment as a proportion of total employment has, according to the HLFS, increased significantly since the beginning of 2006 . This seems to coincide with a volatile levelling-off in the labour force participation rate, as can be seen in the next graph. Hence, volatility in employment has also increased in the last couple of years with large quarterly increases followed by large.

Figure 4: Employment and Leading Indicator of Employment (standard, i.e., excluding the Job Ad Series, last 8 years)

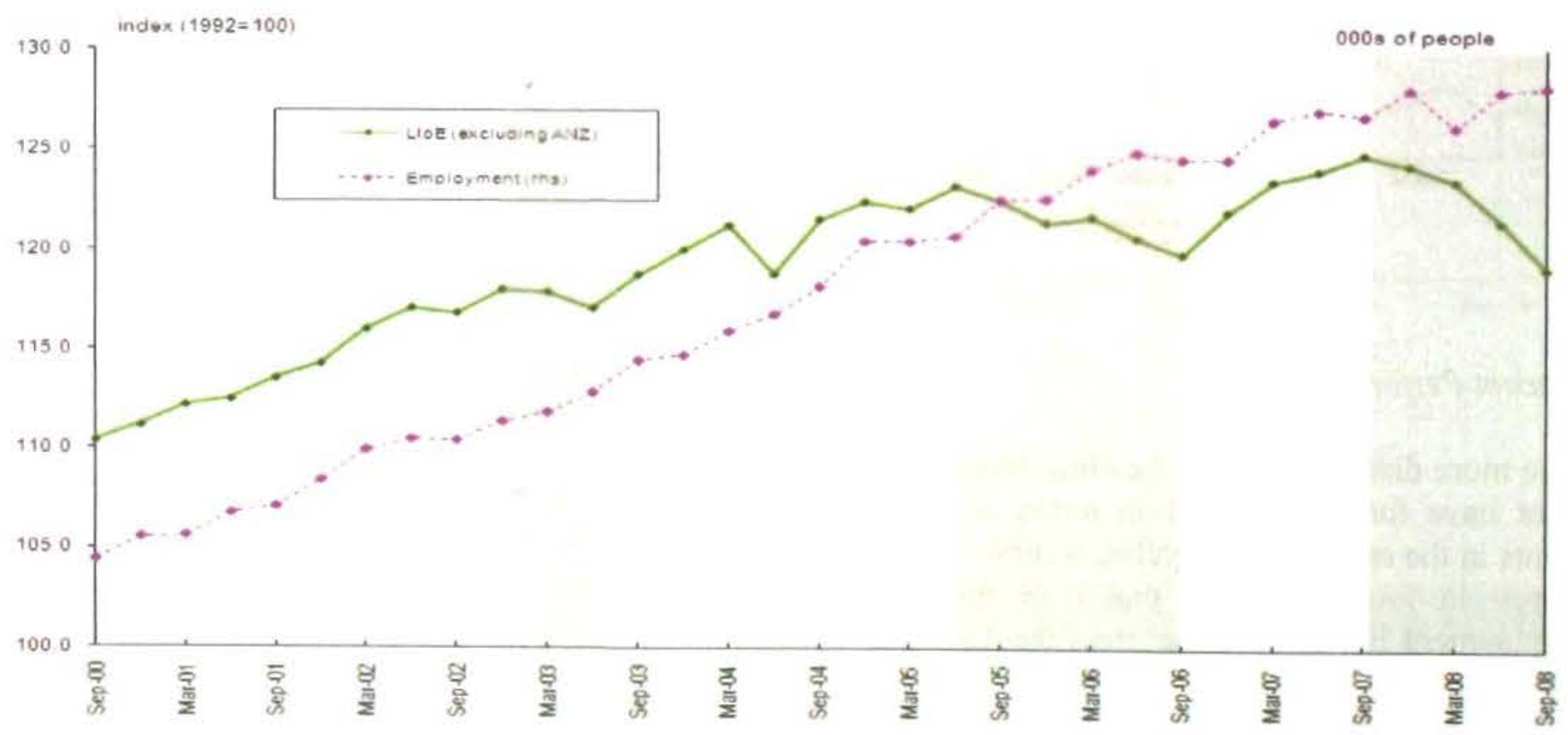

Source: DoL. Statistics New Zealand

The apparent disconnect that is now appearing between the LIoE and employment can then be explained by a volatile but static trend in the labour force participation rate at record heights associated with rising part-time employment perhaps leading to a volatile but static trend in employment.

\section{Forecasting with the Leading Indicator of employment}

The Leading Indicator of Employment can also be used as an employment growth forecasting tool. The results for 1 and 3 quarters out are shown in Table 3. 
Figure 5: Part-time Employment and Labour Force Participation Rates

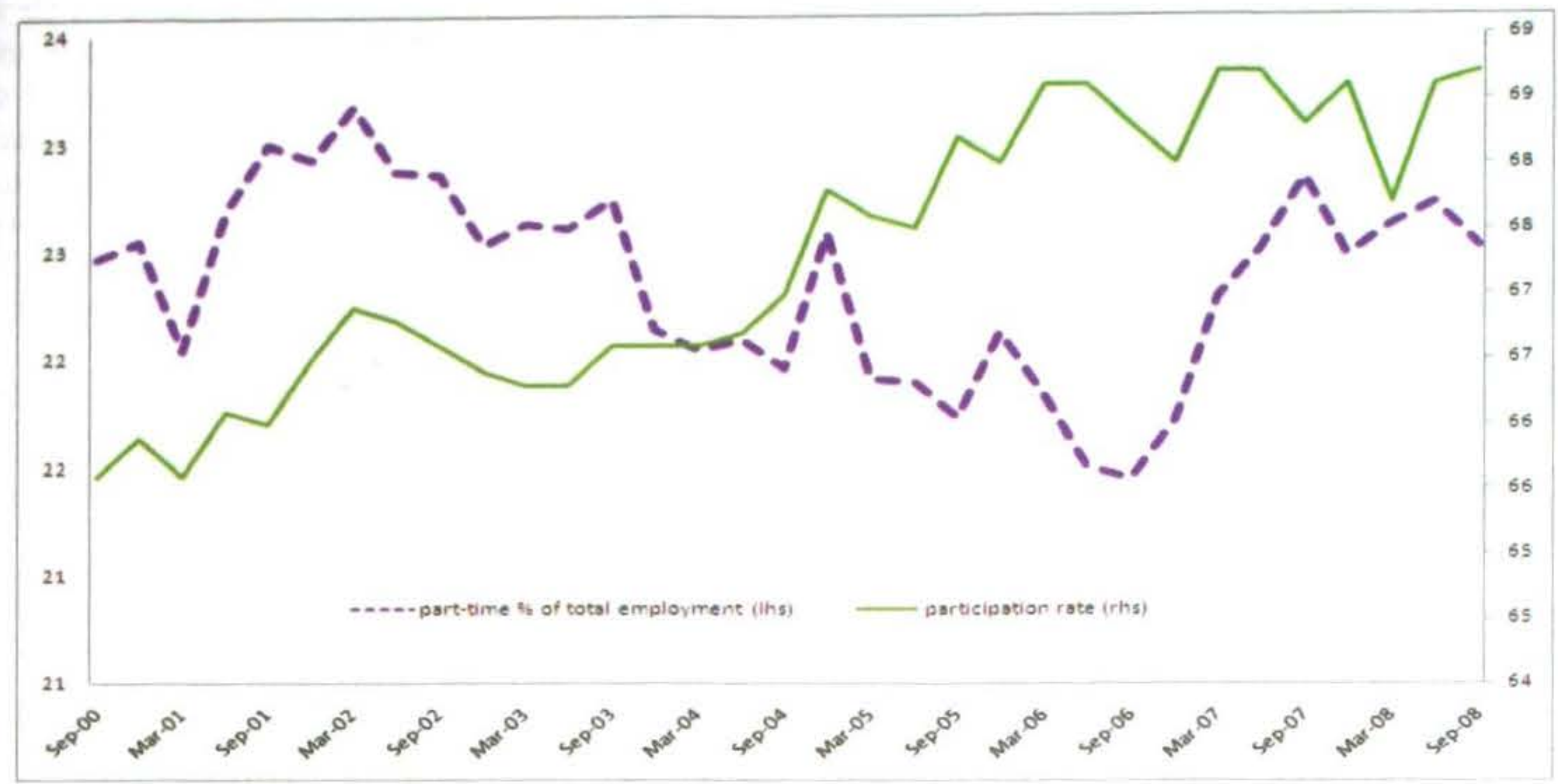

Source: HLFS

Table 3: Forecasting results for quarterly $\%$ change in employment (seasonally adjusted)

\begin{tabular}{|c|c|c|c|c|c|}
\hline & & \multicolumn{2}{|c|}{ Incl Job Vac Ads } & \multicolumn{2}{|c|}{ Excl Job Vac Ads } \\
\hline & & 1 Quarter Ahead & 3 Quarter Ahead & 1 Quarter Ahead & 3 Quarter Ahead \\
\hline & Actual & $\begin{array}{c}\text { Previous \& } \\
\text { current forecast }\end{array}$ & Current forecast & Current forecast & Current forecast \\
\hline $2006 Q 4$ & $0.0 \%$ & $0.1 \%$ & & & \\
\hline 2007Q1 & $1.4 \%$ & $0.3 \%$ & & & \\
\hline 2007Q2 & $0.5 \%$ & $0.2 \%$ & & & \\
\hline 2007Q3 & $-0.3 \%$ & $0.8 \%$ & & & \\
\hline 2007Q4 & $0.9 \%$ & $1.1 \%$ & & & \\
\hline 2008Q1 & $-1.3 \%$ & $0.6 \%$ & & & \\
\hline 2008Q2 & $1.3 \%$ & $0.0 \%$ & & $0.1 \%$ & \\
\hline 2008Q3 & $0.1 \%$ & $0.0 \%$ & & $0.2 \%$ & \\
\hline 2008 Q4 & & $-0.8 \%$ & $-0.4 \%$ & $-0.5 \%$ & $-0.1 \%$ \\
\hline 2009Q1 & & & $0.2 \%$ & & $0.1 \%$ \\
\hline 2009Q2 & & & $-0.3 \%$ & & $-0.3 \%$ \\
\hline
\end{tabular}

It can be seen that using the two Leading Indicators of Employment as a forecast tool yields quarter on quarter employment growth estimates that are broadly negative for the next one and three quarters. However, according to Claus (2006), the dynamic forecasts of three quarters out are less satisfactory given the low explanation of the variation in employment shown in
Table 5 and Table 6.

In formal terms the forecasting model of the Standard LIoE still performs better than the ARIMA model and a VAR model in which the Leading Indicator is included, as can be seen in the next table.

Table 4: Forecast errors of Standard LIoE (excl Job Vac Ads), sample 1996Q3 to 2007Q3

\begin{tabular}{cccc}
\hline & MAE & RMSE & U-Theil \\
\hline Model Used & 0.4631 & 0.5803 & 0.7629 \\
ARIMA & 0.5224 & 0.6365 & 0.8368 \\
VAR & 0.5190 & 0.6595 & 0.8671 \\
\hline
\end{tabular}

Notes:

- RMSE: Root Mean Squared Forecasting Error (RMSE), the smaller the error the better the forecasting ability

- MAE: Mean Absolute Forecasting Error (MAE)), the smaller the error the better the forecasting ability

- U-Theil: Theil Inequality Index, lies between zero and the smaller the value, the better the model performs compared to a naîve forecast of no change 
Table 5: Forecasting statistics with Standard LIoE (excl Job Vac Ads), 1 quarter ahead

\begin{tabular}{|c|c|c|c|c|}
\hline \multicolumn{5}{|c|}{$\begin{array}{l}\text { Dependent Variable: EMP_PC } \\
\text { Method: Least Squares } \\
\text { Date: } 11 / 18 / 08 \text { Time: } 16: 56 \\
\text { Sample (adjusted): } 1987 \mathrm{Q} 32008 \mathrm{Q} 3 \\
\text { Included observations: } 85 \text { after adjustments }\end{array}$} \\
\hline Variable & Coefficient & Std. Error & t-Statistic & Prob. \\
\hline $\mathrm{C}$ & 0.149558 & 0.069748 & 2.144266 & 0.0351 \\
\hline LIENZ1_PC $(-1)$ & 0.151656 & 0.054223 & 2.796890 & 0.0065 \\
\hline LIENZ1_PC(-2) & 0.110172 & 0.053590 & 2.055855 & 0.0431 \\
\hline LIENZ1_PC(-3) & 0.185613 & 0.057509 & 3.227566 & 0.0018 \\
\hline LIENZ1_PC $(-4)$ & 0.101475 & 0.055001 & 1.844962 & 0.0688 \\
\hline EMP_PC(-3) & 0.248693 & 0.102309 & 2.430797 & 0.0173 \\
\hline R-squared & 0.397827 & Mean dependent var & & 0.341552 \\
\hline Adjusted R-squared & 0.359715 & S.D. dependent var & & 0.715913 \\
\hline S.E. of regression & 0.572858 & Akaike info criterion & & 1.791615 \\
\hline Sum squared resid & 25.92512 & Schwarz criterion & & 1.964037 \\
\hline Log likelihood & -70.14363 & Hannan-Quinn criter. & & 1.860968 \\
\hline F-statistic & 10.43830 & Durbin-Watson stat & & 1.818860 \\
\hline Prob(F-statistic) & 0.000000 & & & \\
\hline
\end{tabular}

Table 6: Forecasting Statistics with Standard LIoE (excl Job Vac Ads), 3 quarter ahead

\begin{tabular}{|c|c|c|c|c|}
\hline \multicolumn{5}{|c|}{$\begin{array}{l}\text { Dependent Variable: EMP_PC } \\
\text { Method: Least Squares } \\
\text { Date: } 11 / 18 / 08 \text { Time: } 16: 56 \\
\text { Sample (adjusted): } 1987 \mathrm{Q} 2008 \mathrm{Q} 3 \\
\text { Included observations: } 86 \text { after adjustments }\end{array}$} \\
\hline Variable & Coefficient & Std. Error & t-Statistic & Prob. \\
\hline $\mathrm{C}$ & 0.174392 & 0.074715 & 2.334105 & 0.0220 \\
\hline LIENZ2_PC(-1) & -0.960335 & 0.400020 & -2.400715 & 0.0186 \\
\hline LIENZ2_PC $(-4)$ & 0.649000 & 0.410584 & 1.580674 & 0.1178 \\
\hline EMP_PC $(-3)$ & 0.480317 & 0.101722 & 4.721866 & 0.0000 \\
\hline R-squared & 0.282426 & Mean dependent var & & 0.335443 \\
\hline Adjusted R-squared & 0.256173 & S.D. dependent var & & 0.713940 \\
\hline S.E. of regression & 0.615741 & Akaike info criterion & & 1.913414 \\
\hline Sum squared resid & 31.08920 & Schwarz criterion & & 2.027569 \\
\hline Log likelihood & -78.27678 & Hannan-Quinn criter. & & 1.959356 \\
\hline F-statistic & 10.75796 & Durbin-Watson stat & & 1.689700 \\
\hline Prob(F-statistic) & 0.000005 & & & \\
\hline
\end{tabular}

Forecasting with the Expanded LIoE (not shown here) is less robust with forecast errors higher than the ARIMA model but still lower than the VAR model.

\section{Conclusions and thoughts for further development}

A set of preliminary Leading Indicator of Employment for New Zealand has been constructed by Claus (2006). This paper describes how one version of this set has been maintained and employed at DoL.
The paper suggests that the re-introduction of the Job Ads series, formerly maintained by ANZ, does not seem to add much in terms of giving advanced warnings of turning points in the employment series nor in terms of reduced forecast errors, at this stage. Continuous monitoring will be required as this conclusion could change in the future.

In spite of a well behaved historic track record, with or without the Job Ads series, there has been a marked disconnect recently between the LIoE and employment series. On two occasions, of which one is still ongoing, 
the LIoE has confirmed a downturn while employment did not do so in the generally accepted lead times. This apparent disconnect can perhaps be explained by a volatile but static trend in the labour force participation rate near the top of its range, associated with rising parttime employment leading to a volatile but static trend in employment. It will be interesting to see what happens to the performance of the two LIoE described in this note at higher unemployment rates.

Alternatively, it would be possible to try one of the other models suggested by Claus (2006) and Claus \& Claus (2007). However, both studies found that the concordance method that is currently trialled at DoL and described in this report, ranks well in terms of forecasting performance and is perhaps the most transparent methodology to policy makers and labour market practitioners.

What is then left to improve the performance is to try fit new series in the current index system, so as to improve its recent performance without compromising its historic track record. A large number of close to 100 series were considered by Claus (2006) with only half a dozen retained, so there is ample scope for further exploration.

\section{Notes}

1. Work Directions, Department of Labour. Comments by Simon McLoughlin are gratefully acknowledged. The views expressed in this paper do not necessarily represent those of the Department of Labour and any remaining errors are the author's responsibility,

\section{References}

Australian Bureau of Meteorology: http://www.bom.gov.au/climate/current/soihtm1.s html.

Claus, E. (2006): Two leading indexes of New Zealand employment, Report prepared for the Department of Labour.

Claus, E. \& Claus I. (2002), How many jobs? A leading indicator model of New Zealand employment, New Zealand Treasury Working Paper, 02/13, http://www.treasury.govt.nz/publications/researchpolicy/wp/2002/02-13.

Claus, E. \& Claus I. (2007), Six leading indicators of employment for New Zealand, Centre for Applied Macroeconomic Analysis. CAMA Working Paper 17/2007, http://cama.anu.edu.au.

DEEWR Monthly Leading Indicator of Employment Latest Release

November 2008 , Release http://www.workplace.gov.au/workplace/Publicati ons/LabourMarketAnalysis/LeadingIndicatorEmpl oyment/DEEWRMonthlyLeadingIndicatorofEmpl oyment-LatestRelease.htm.
Silverstone B. \& Wall, V. (2008): Job vacancy monitoring in New Zealand, Paper contributed to the LEW Conference 2008, Wellington, http://www.victoria.ac.nz/geo/about/news-andevents/lew13/programme.html.

\author{
Author \\ Dirk van Seventer \\ Work Directions \\ Department of Labour \\ PO Box 3705 \\ Wellington \\ dirk.vanseventer@dol.govt.nz
}

